\title{
Sindicato: \\ uma entidade ainda desconhecida do psicólogo
}

\author{
Sérgio Antônio da Silva Leite \\ Professor de Psicologia Educacional da \\ Universidade de Mogi das Cruzes e \\ diretor do Sindicato dos Psicólogos no \\ Estado de Såo Paulo.
}

Historicamente, os sindicatos surgiram como entidades fundadas e mantidas pelos próprios trabalhadores para defenderem seus interesses nas relaçōes de traba. lho. Precisamente, foi a partir do século XIX, com o surgimento das sociedades industrializadas na Europa e Estados Unidos, que os trabalhadores das indústrias foram levados a organizarem-se em associações com o objetivo de se defenderem da exploraçāo da măo-de-obra e reivindicarem melhores condiçסes de trabalho. Tais associações, a princípio proibidas pelo Estado, através da constante luta assumida pelos trabalhadores, foram sendo paulatinamente reconhecidas não só como legítimas, mas também como necessárias para as relaçōes entre o capital e o trabalho.

Assim, nas sociedades industrializadas, a história do sindicalismo tem se confundido na prática com a própria história da classe trabalhadora, a qual tem se utilizado daquelas instituiçōes como um instrumento de organizaçăo $\mathrm{e}$ luta.

Entendem-se, portanto, nos paises industrializados, a constante tentativa do Estado, representando os interesses dos setores economicamente dominantes, em manter o controle sohre os sindicatos,seja através da cooptaçáa de setores da classe trabalhadora - os chamados pelegos -, seja através da legislação ou da intervençāo direta por meio de mecanismos de repressāo, nos casos extremos.

No Brasil, a história do sindicalismo năo foi diferente. Iniciandose timidadamente neste século, como consequência da industrialização, foi no período do Estado Novo de Vargas (1937 a 1945) que os sindicatos dos trabalhadores foram submetidos a um rígido controle, quando a sociedade política lhes impóe uma legislaçăo inspirada no modelo italiano fascista de Mussolini. Deve-se notar que essas leis, basicamente continuam as mesmas até hoje, colocando as associaçoes e sindicatos atrelados à autoridade do Ministério do Trabalho, o qual detém plenos poderes de intervençāo sob os mais variados pretextos.

Após 1964, o controle do Estado sobre os sindicatos dos trabalha. dores tornou-se tăo intenso, que praticamente durante vários anos foram paralisadas e reprimidas a maioria das entidades sindicais, através de processos de intervenção direta ou da transformaçăo em entidades meramente burocráticas e assistenciais. $O$ período do "milagre brasileiro" coincide assim, com a época em que os sindicatos foram impedidos de desempenhar seu papel de defesa dos interessos econômicos e políticos dos trabalhadores. Isto facilitou a ação do Estado, que promoveu o achatamento salarial dos traba. lhadores brasileiros, com sérios efeitos até hoje.

Somente os anos finais da déca. da de 70 , teve início uma reação a partir das bases do movimento operário, restrita a principio aos grandes centros industriais, reivindicando mudanças na lei sala. rial e na própria estrutura e fun. cionamento dos sindicatos. Tal reaçāo tem-se concretizado através da organização de movimentos de oposição às antigas diretorias dos sindicatos, que durante os últimos 15 anos mantiveram-se subservientes aos interesses do Estado.

Tal reação, embora com atraso, também começou a ocorrer nas chamadas categorias de profissionais "liberais", que durante esses anos passaram por um processo de proletarizaçāo, caracterizado pelo aumento da proporção de profissionais assalariados e, digase de passagem, progressivamen. te mal-remunerados.

Esta é a realidade que também vem ocorrendo com os psicólogos no Brasil. A partir do final da década de 70 começaram a surgir associaçōes em vários Estados, al. gumas já transformadas em sindicatos, da mesma forma que se iniciou a articulação de grupos de oposiçấo às antigas diretorias das entidades já existentes. 


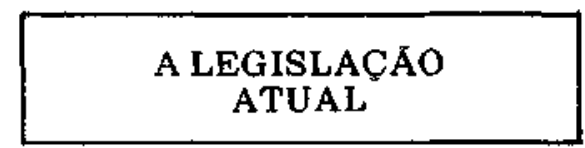

Atualmente as prerrogativas e deveres dos sindicatos estăo especificados pela CLT, que determina também todos os aspectos relacionados ao seu funcionamento.

De acordo com a lei, săo prerrogativas dos sindicatos: a) representar perante as autoridades, os interesses gerais ou individuais dos seus associados; b) celebrar acordos coletivos de trabalho; c) eleger ou designar representantes da categoria; d) colaborar com o Estado, com-órgáos técnico e consultivo, no estudo de soluçóes dos problemas relacionados com a categoria; el impor contribuiçōes a todos os profissionais que participam da categoria representada, ou seja, todos devem pagar a contribuiçāo sindical, independente de serem ou náo sindicalizados.

A mesma lei (CLT), define ainda os seguintes deveres do sindicato: a) colaborar com os poderes públicos no desenvolvimento da solidariedade social; b) manter as sistência judiciária aos sócios; c) promover a conciliaçāo nos dissídios de trabalho; d) promover, na medida do possível, através de convênios com entidades assistenciais ou por conta pró. pria, a cooperaçāo operacional na empresa e a integraçăo profissional na classe. A este último item, foram acrescidos os deveres de promover a fundação de coopera. tivas de consumo e de crédito, além de escolas de alfabetizaçăo e pré-vocacionais.

Como se pode observar, a legislação atual representa um dos ins. trumentos através do qual o Estado tenta manter controle sobre o sindicato. É evidente a intençăo de transformar o sindicato numa

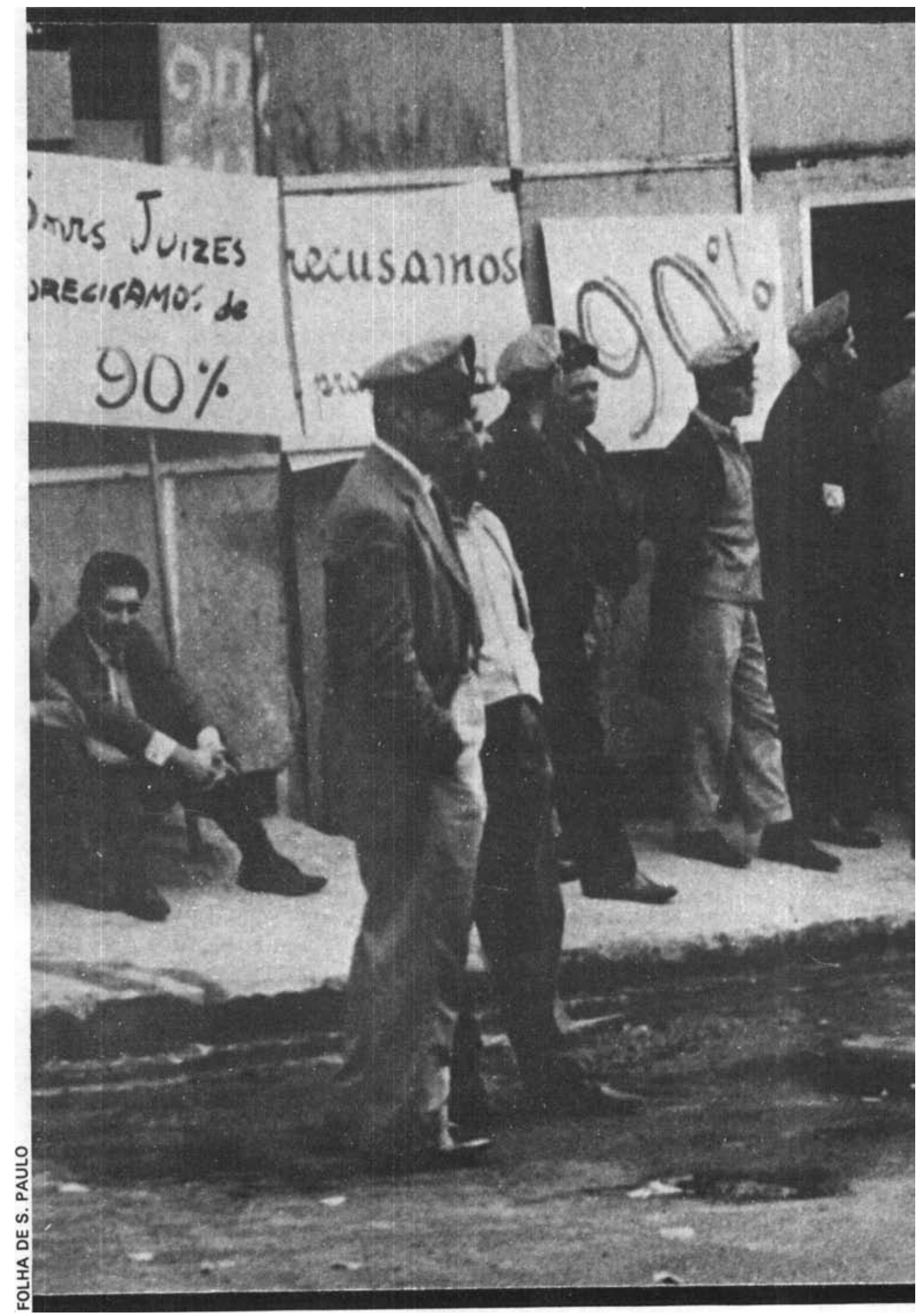




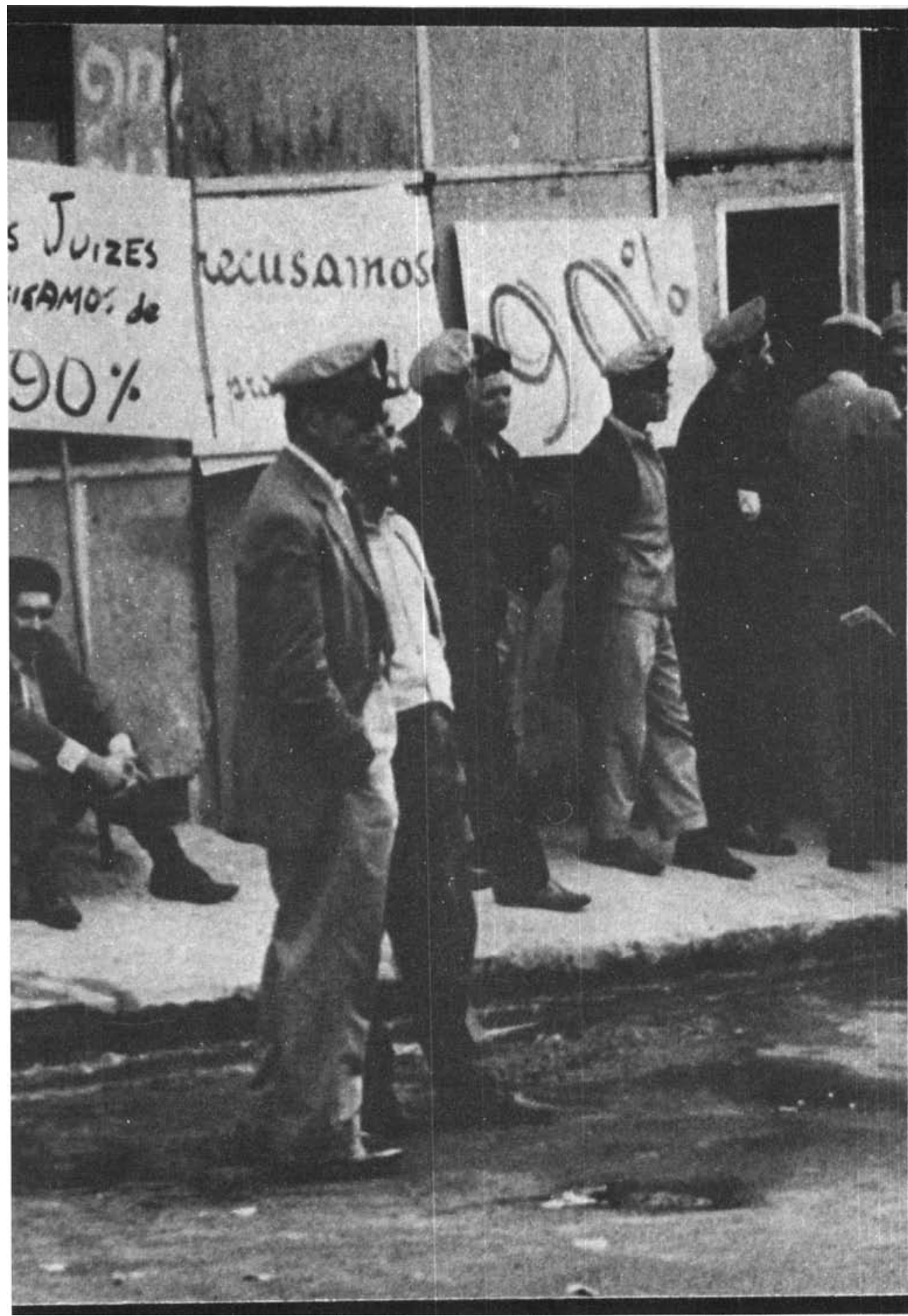

entidade colaboradora do Estado e ao mesmo tempo assistencial em relação aos associados.

Deve-se ressaltar o efeito da úl. tima prerrogativa citada pela lei, que obriga todo profissional a pa. gar a contribuiçăo sindical independente de ser sindicalizado. Es. ta é a razấo pela qual todo psicólogo paga obrigatoriamente a contribuiçâo sindical. Porém isto năo significa ser sindicalizado. Para tanto, o profíssional deverá procurar o sindicato ou a associaça de sua regiaso, se houver, e filiar. se, pagando também a anuidade. Tal medida, da mesma forma, foi inspirada no modelo sindical fascista na Itália, que tinha como objetivo manter o sindicato com dinheiro, mas politicamente com pouco poder de representação, ou seja, com poucos sócios. Isto porque associar-se ao sindicato im. plica em pagar a segunda taxa - a anuidade, além da contribuição obrigatória.

Tal medida vem demonstrar uma outra forma de atrelamento sindical ao Estado: a dependência econômica, que afeta principalmente os sindicatos com um número pequeno de associados.

Um dos aspectos deste tipo de atrelamento relaciona-se às formas de cobrança e distribuição da contribuiçăo sindical obrigatória acima citada. Segundo a CLT, essas contribuiçóes, calculadas em termos do maior valor de referéncia para os profissionais liberais, såo cobradas no início do ano, e depositadas numa conta corrente na Caixa Económica Federal intitulada "Depósitos da Arrecadaçăo da Contribuiçăo Sindical". devendo o Ministério do Trabalho ser informado a respeito dos créditos ocorridos. Esta importância é dividida da seguinte forma: $5 \%$ para a Confederaçáo correspon. 
dente; $15 \%$ para a Federaçao correspondente; $60 \%$ para o respectivo sindicato e $20 \%$ para a "Conta Especial Emprego-Salário", administrada pelo Ministério do Trabalho, sem que os sindicatos tenham qualquer participação.

No caso dos psicólogos, a categoria faz parte da Confederaçăo Nacional das Profissoes Liberais que fica com $20 \%$ da contribuiçăo sindical dos profissionais, visto nāo existir ainda a Federação de Sindicatos de Psicólogos. Assim, a Confederação recebe também a porcentagem prevista para a Federaçao, a qual só poderá ser fun. dada a partir da existéncia de 5 sindicatos de psicólogos.

Nog Estados em que não há sindicato, o percentual - $(60 \%)$, que lhe caberia permanece destinada a "Conta Especial EmpregoSalário", administrada pelo Ministério.

Observa-se portanto, que o controle da arrecadaçáo e administração deste dinheiro, o qual somado às demais categorias representa um volume fabuloso, permanece com o Ministério do Trabalho, sem que as entidades tenham participaçāo. Além disso, deve-se ressaltar que a CLT determina as finalidades em funçăo das quais a contribuiçấo sindical pode ser gasta pela entidade, constituindo-se basicamente por atividades assistenciais, culturais e esportivas.

\begin{tabular}{|c|}
\hline POR QUE UM \\
SINDICATODE \\
PSICOLOGOS? \\
\hline
\end{tabular}

A questão sem dúvida, é perti. nente. Afinal, dadas todas as condicóes acima arroladas de atrelamento ao Estado, é possível um sindicato que venha realmente de- fender os interesses de uma categoria? Ou ainda, qual a importán. cia do um sindicato para as categorias ditas "liberais", como os psicólogos?

Inicialmente se deve ressaltar que, na prática, o controle que o Estado tenta desempenhar sobre - sindicato não é automático nem simples. Pelo contrário. Pode-se afirmar que o Estado, com todos os seus meios, tenta estabelecer essas relaçoes de controle, mas sua consecuçăo vai depender de uma série de fatores, entre eles o nivel de consciência política da categoria ou parte dela, o qual na prática pode frustrar as intençôes do Estado.

Assim, como historicamente tem sido demonstrado, o Estado vai tentar o controle sobre qual. quer iniciativa de organização dos trabalhadores, incluindo os cha. mados "liberais". Em outras palavras, o problema do controle do Estado vai depender de como os grupos de profissionais, na práti. ca, venham a se organizar e utilizar o espaço de participaçấo que o sindicato, sem dúvida, representa.

Da mesma forma, deve-se ressaltar que também os profissionais "liberais" estão sujeitos a leis e regras formuladas pelo Es. tado, o que demostra, na prática, que antes de "liberais", sâo trabalhadores, e como tais deparam. se com urna série de problemas tais como falta de condiçoes de trabalho, baixo salários, desemprego etc. Este quadro gera a necessidade de uma entidade de defesa dos direitos e interesses dos profissionais, pois tais problemas nâo podem ser resolvidos pela aça isolada dos mesmos.

Além disso, há uma significativa parcela de psicólogos que são assalariados, parcela esta que tende a aumentar, o que vem reforcar a necessidade do sindicato.

Na prática, portanto, o sindicato pode ser o espaço para os profissionais discutirem questoes como condiçoes de trabalho, desemprego etc., e, ao discuti-las, estarăo analisando a própria sociedade, uma vez que as condiçōes de trabalho relacionam-se diretamente com a questāo da qualidade de serviço prestada à populaçăo $\mathrm{e}$, portanto, com a própria condiçăo desta populaçáo.

Talvez, no presente, seja esta uma das principais funçōes de um sindicato para uma categoria como a dos psicólogos: organizar e aglutinar os profissionais em torno da discussáo da própria sociedade, através da análise e constante reavaliação do tipo de servico prestado à sociedade, possibilitando assim que estes profissionais melhorem seu nível de consciéncia social bem como consciência da necessidade e importáncia do seu próprio trabalho.

Neste sentido, 0 sindicato situa-se como uma instancia politizadora e educativa para os trabalhadores, inclusive os "liberais", pois discutir as suas condiçoes de trabalho é em última inståncia discutir as condições da própria populaçáo.

E esta luta é constante. A melhoria da qualidade do serviço prestado por uma categoria depende do seu nível de consciência, que por sua vez pode ser aprimo. rado e ampliado pela constante relação entre açăo e reflexăo. E o sindicato pode representar um espaço concreto para tal reflexăo.

Além disso o sindicato pode ser um instrumento de engaja. mento no movimento nacional dos trabalhadores, uma vez que os problemas trabalhistas, em última instância, afetam a todos.

O Estado, por sua vez, sabe da 
força política da uniảo dos trabalhadores em torno de sindicatos nåo atrelados. Isto explica seu contínuo esforço visando manter esse atrelamento.

\section{COMO SE \\ ORGANIZA \\ UM SINDICATO?}

Há um longo processo para a criação de um sindicato. Segundo a lei, um sindicato só pode ser formado a partir da associaçăo de profissionais de uma determinada região ou Estado. Para se fundar

CRP-06

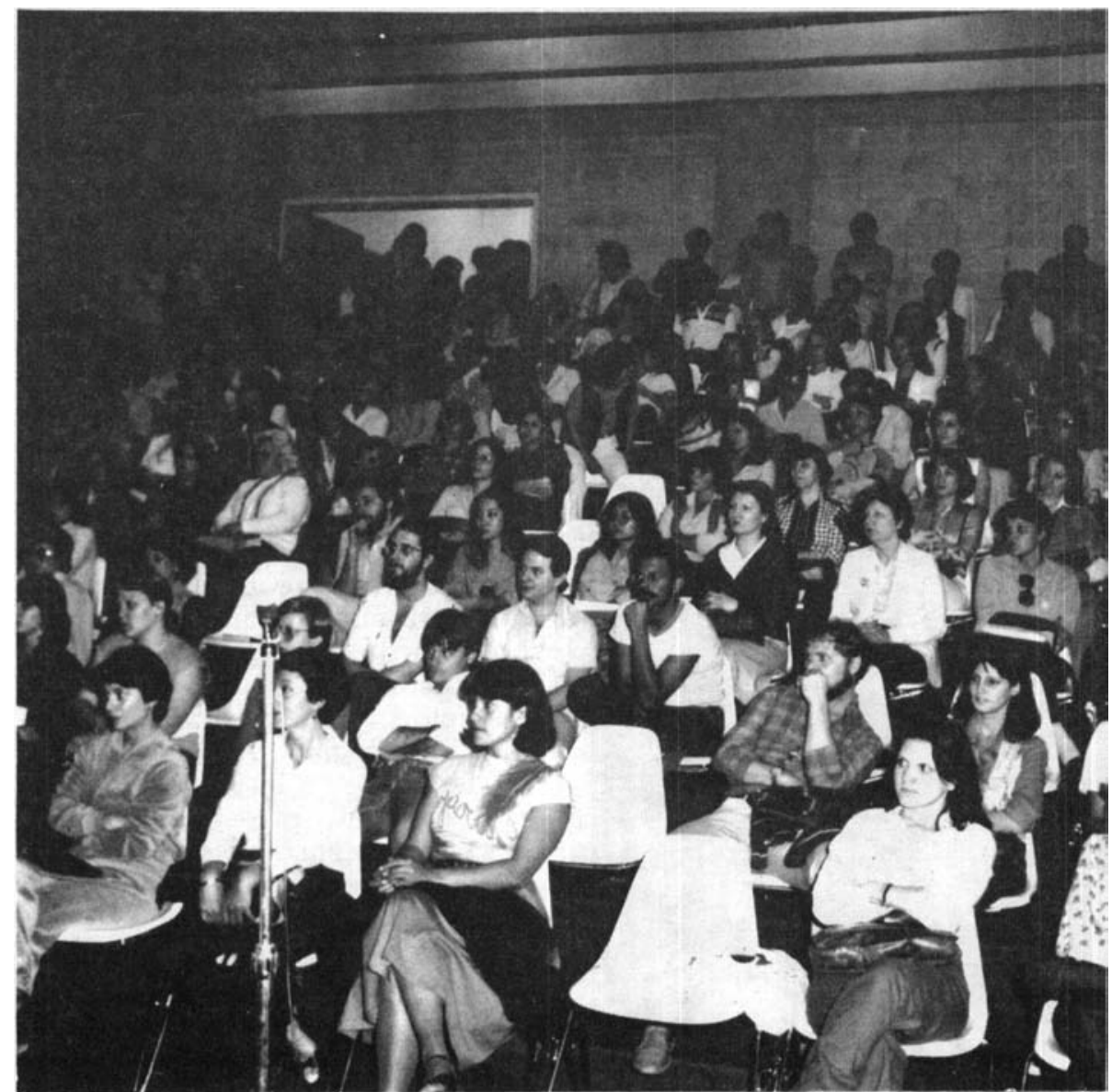

tal associaçáo, é necessária a participaçăo de $1 / 3$ dos profissionais da regiaxo, elaboraçáo do estatuto padrăo, fixaçāo das mensalidades e registro no Ministério do TrabaTho. Só a partir daí pode-se aspirar à sua transformaçăo em sindicato.

Legalmente a associaçăo pro. fissonal tem a funçăo de preparar a criaçăo do sindicato, funcionando como um momento antecipatório do mesmo. Além disto, pode atuar na defesa de profissionais, embora suas conquistas não sejam generalizadas para toda a categoria.
$\mathrm{Na}$ prática, à semelhança do sindicato, a associaçăo profissional também pode desempenhar um papel político mais relevante no sentido da organização dos profissionais em torno de seus problemas.

Para transformaçăo em sindicato, primeiramente é preciso que a Assembléia da Associação Profissional aprove a proposta; em seguida é necessário adaptar o estatuto à legislação sindical e final. mente requerer a autorizaça do Ministério do Trabalho. A lei ainda exige dos diretores da associaçăo provas de boa conduta e de que năo professam ideologias incompatíveis com as instituiçסes e interesses da Naçăo.

Caberá ao Ministro do Trabalho autorizar a transformaça da associaçăo profissonal em sindicato, através da carta de reconhecimento sindical, levando-se em conta, entre outros, os seguintes critérios: número de associados (permanece a exigência de $1 / 3 \mathrm{de}$ profissionais da regiăo), servicos sociais fundados e mantidos e. 0 valor do património.

Com relação às federaçסes, sua organizaçáo é facultada aos sindicatos que representam categorias económicas ou profissionais homogêneas desde que existam pelo menos 5 sindicatos.

Por outro lado, as confederacóes poderáo ser organizadas com - mínimo de 3 federaçōes e terăo sede na capital da República. Além disso, a lei já determina os tipos de confederaços tanto dos sindicatos dos empregadores quanto dos empregados. No caso dos liberais, existe por lei a Confederaçáto Nacional dos Profissio. nais Liberais, a quem os psicb́logos jāo estăo incluídos por força de lei, a qual fica com $20 \%$ das 


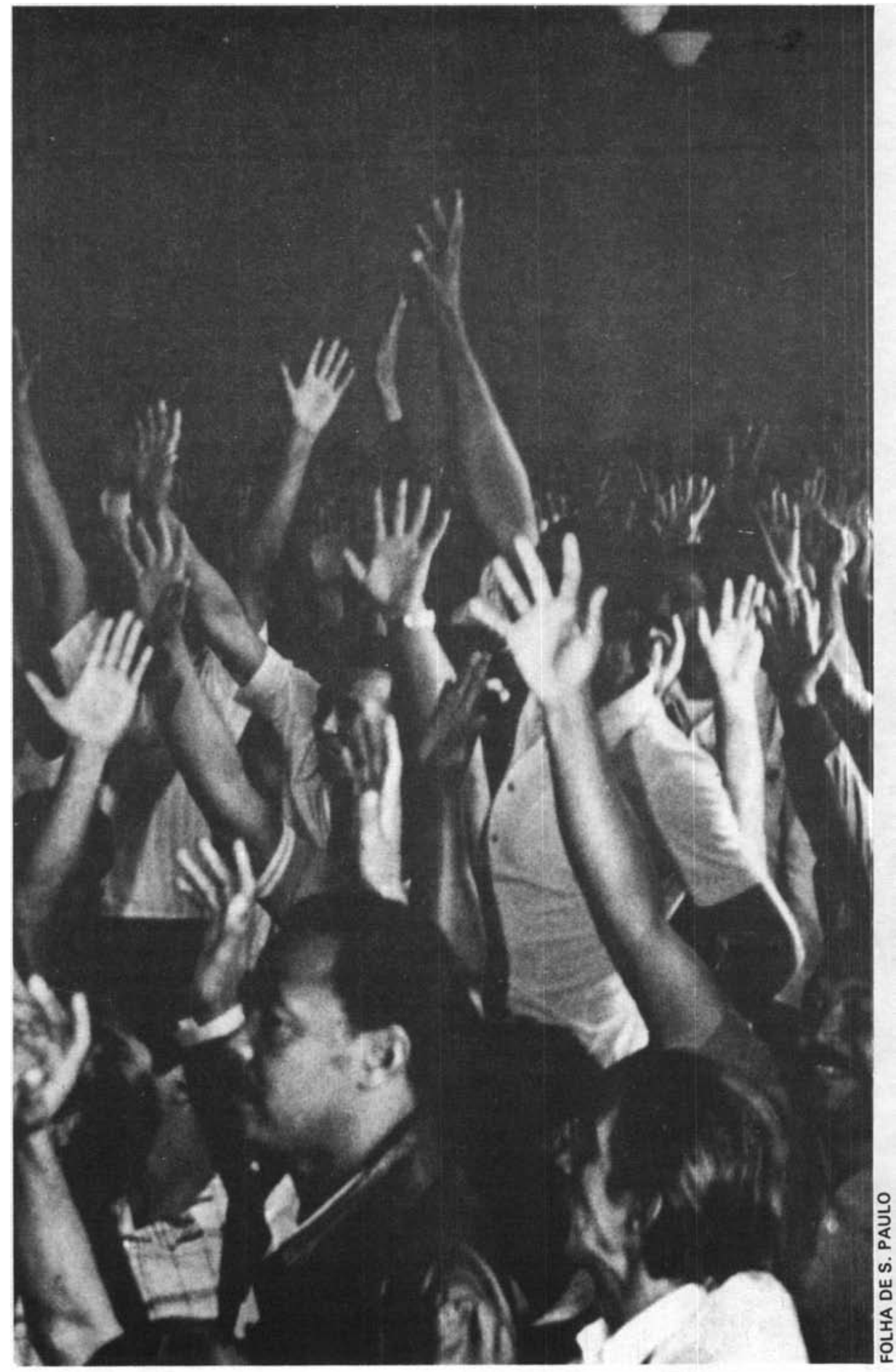

contribuiçōes sindicais de todos os profissionais.

O que se observa novamente $\dot{e}$ o controle que o Estado tenta de. sempenhar também neste nivel, na medida em que a investidura sindical de uma associação de profissionais é de decisão final do próprio Ministro do Trabalho, ou seja, na prática é o Estado que decide e controla os mecanismos de formação dos sindicatos, federaçōes e confederaçōes.

\section{SITUAÇĀO DAS ENTIDADES NO BRASIL}

Atualmente, existem sindicatos de psicólogos nos Estados de São Paulo, Rio Grande do Sul, Rio de Janeiro e Paraná; associações profissionais em Minas $\mathrm{Ge}$ rais, Distrito Federal, Pernambu. co, Espírito Santo, Ceará, Mato Grosso do Sul, Goiás e associa. çóes de Psicólogos em Alagoas, Rio Grande do Norte, Bahia e Piauí.

Há cerca de três anos foi iniciado um trabalho de articulação nacional pelas entidades. Os primeiros contatos iniciaram-se em 1980 , durante a SBPC, onde foi realizada uma reunião das entida. des presentes para discutir a questão da luta contra o Projeto Julianelli e a implantação do currículo mínimo para os cursos de Psicologia. A partir daí, evidenciou-se a importância de se manterem encontros mais periódicos entre as entidades para discu. tir os problemas que afetam a categoria a nível nacional.

Em novembro de 81 foi realiza. do o I Encontro Nacional das Entidades Sindicais de Psicólogos, em São Paulo, com a presença dos sindicatos de São Paulo, Rio de 
Janeiro e Rio Grande do Sul e das associaços do Espírito Santo e Distrito Federal. Discutiu-se a questáo do Imposto de Renda além de problemas relacionados com o mercado de trabalho.

O II Encontro foi realizado em Brasília, em abril de 82 , quando ainda se estava em plena campanha visando ao reconhecimento do psicólogo pelo Imposto de Renda. Discutiram-se ainda questoes da articulação com o movimento sindical nacional. Participaram as entidades de Minas Gerais, Ceará e Pernambuco, além das presentes ao encontro anterior, exceto a do Espírito Santo.

Ainda em 82, no mês de outubro, ocorreu o III Encontro, no Rio de Janeiro, onde se deu continuidade à discussão das questoes do mercado de trabalho, dissídio, salário mínimo profissional e desemprego. Duas associaçoes par. ticiparam pela primeira vez: Rio Grande do Norte e Alagoas.

Finalmente, o IV Encontro foi realizado em maio de 83 , no Recife, enquanto o $V$ Encontro foi realizado em junho de 84, em Brasília. Uma decisão importante assumida no IV Encontro foi a realizaçăo de encontros regionais, devido às dificuldades financeiras em se manterem Encontros Nacionais com a mesma frequência anterior. Assim, as entidades foram divididas em 2 grupos, respeitando-se a proximidade geográfica, com a tarefa de realizarem encontros regionais.

\section{O PRINCIPAL PROBLEMA: A PARTICIPACAO DOS PROFISSIONAIS}

O maior problema que as associaçoes e sindicatos de psicólogos tếm enfrentado diz respeito à participaçăo da categoria. Observa- se que na maioria das entidades apenas uma pequena porcentagem de profissionais é associado e, desse grupo, nem todos participam ativamente das atividades desenvolvidas. Tal fato tem-se verificado também nas eleiçoes das entidades onde tem sido observado, em algumas delas, alto indice de ausência. Portanto este é o quadro: uma pequena porcentagem filia-se, e, desta, somente uma parcela participa.

Por que isto ocorre? Como superar tal situaçăo?

$\mathrm{Na}$ realidade, este problema não é especificico das entidades de Psicólogos. Dados estatísticos têm demonstrado que em outras categorias a porcentagem dos associados nos sindicatos também é baixa. $O$ próprio Departamento Intersindical de Estatística e Estudos Sócio-Económicos tem revelado que nos sindicatos que apresentam altas taxas de sindicalizaçăo, tais indices situam-se em torno de $15 \%$ a $20 \%$ da categoria abrangida, com raras exceçōes. Portanto o problema parece que afeta todo o sindicalismo brasileiro. A questăo do sindicato ainda provoca muitos preconceitos e receios em vários setores da população, inclusive a própria classe trabalhadora.

No caso dos psicólogos, algu. mas hipóteses específicas poderiam ser discutidas. Uma delas diz respeito ao significado que o proprio trabalho tem para a maioria da categoria. A pesquisa realizada pelo DIEESE sobre o "Perfil do Psicólogo no Estado de Sáo Paulo" demonstra que, pelo menos naquele Estado, o conceito de trabalho está muito relacionado com satisfaçáo pessoal, aprimoramento moral, ajuda ao próximo, status social e "bico". Ou seja, o trabalho năo é visto pela maioria como uma forma de contribuiçăo social e como consequéncia a profissâo năo é assumida como tal.

Acrescente-se ainda o fato de ser uma categoria formada fundamentalmente por mulheres, da qual $70 \%$ (dados de Sáo Paulo) năo sobrevivem da renda que ganham como psicólogos, representando seu salário uma comple. mentação ao do cônjuge ou à mesada do pai.

$O$ fato de a maioria da categoria não assumir a profissăo em toda a sua plenitude, tem gerado uma situaçáo de desmotivação e desvalorizaçăo dos problemas trabalhistas que afetam os profissio. nais, como as condiçes ruins de trabalho, baixo salário, desemprego etc. Uma vez que tais ques. tờes nâo têm recebido a devida im. portância, a questão sindical consequentemente também não receberá, permanecendo estranha ainda para a maioria dos profissionais, embora quase todos reco. nheçam verbalmente a necessidade do sindicato (Dieese - SP).

Tais fatores certamente ajudarâo a compreender melhor a situa. çăo da categoria dos psicólogos, mas não explicam a auséncia do profissional nos sindicatos e associaçðes. $O$ problema central, sem dúvida, é a questáo da consciência que se tem a respeito das relaçoes sociais, dos problemas que afetam a populaçáo, da importáncia social do trabalho, da relevån. cia da profissấ assumida, questớs estas que refletem o próprio compromisso político do profissional. Todos esses problemas também dizem respeito ao psicólogo, que embora se situe como "liberal", é antes de tudo um trabalhador que enfrenta sérias difi. culdades no presente momento. $O$ sindicato pode vir a ser um impor. tante instrumento de organizaçăo, de luta e conquistas para a categoria. 

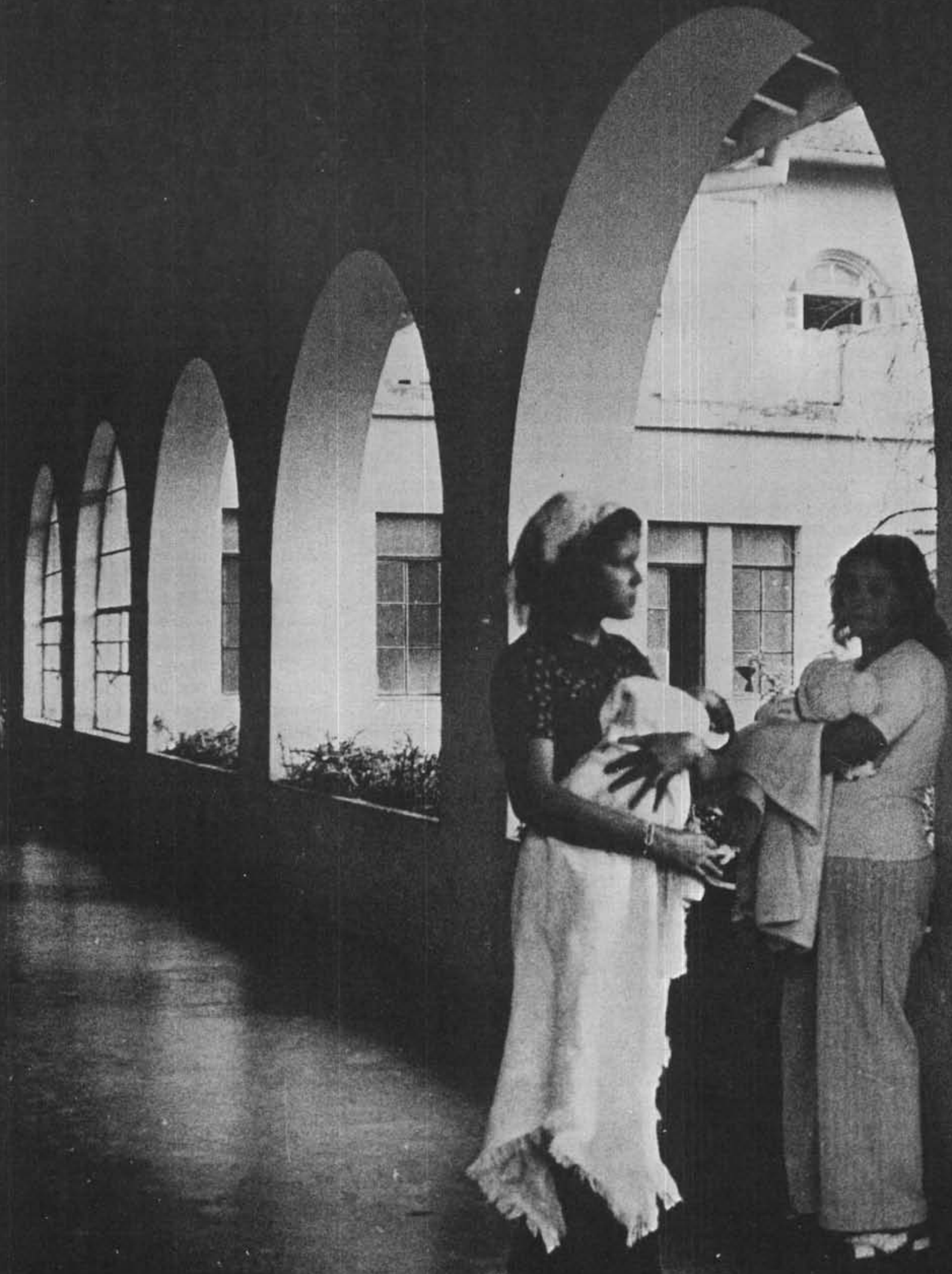